normal immunoglobulin (HNIG) to household and sexual contacts is important. ${ }^{5}$ Hepatitis A vaccine has recently been recommended in the United Kingdom for homosexual men. ${ }^{5}$ Our findings provide some evidence to support its use among this group.

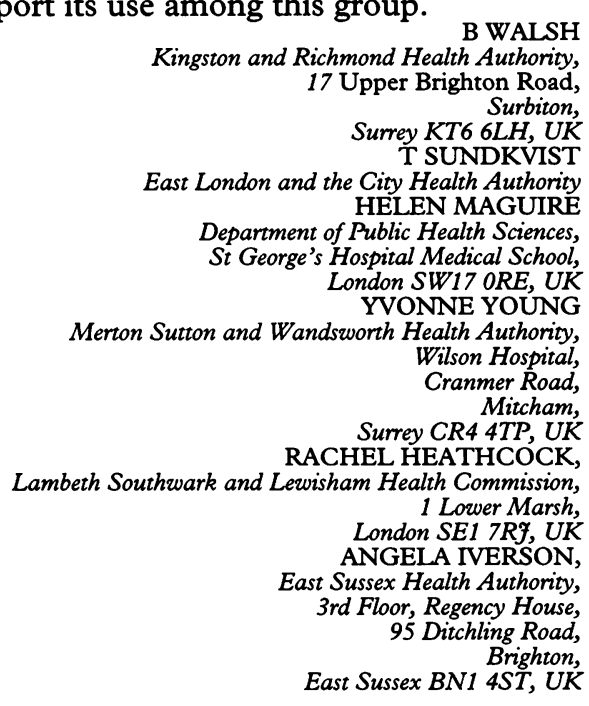

Address correspondence to: $\mathrm{Dr} H$ Maguire, CDSC (Thames), 40 Eastbourne Terrace, London W2 3QR, UK.

1 Mindel A, Tedder R. Hepatitis A in homosexuals. $B M \mathcal{F}$ 1981;282:1666

2 Kani J, Nandwani R, Gilson R, Johnson AM, Maguire HC, Tedder RS. Hepatis A virus infection among homosexual
Teden Tedder RS. Hepatis A virus
men. BMF 1991;302:1399.

3 Corey L, Holmes KK. Sexual transmission of Hepatitis A in homosexual men. N Engl F Med 1980;302:435-8.

4 Henning KJ, Bell E, Braun J, Barker ND. A communitywide outbreak of Hepatitis A: risk factors for infection among homosexual and bisexual men. Am $\mathcal{F}$ Med 1995; 99:132-6.

5 Immunisation Against Infectious Disease. London: HMSO 1996.

Accepted for publication 7 August 1996

\section{Services for female prostitutes in genitourinary medicine clinics in the UK}

Prostitutes may be at increased risk of sexually transmitted diseases and HIV infection as a result of their numbers of sexual partners, although the risks vary. ${ }^{1-3}$ Genitourinary medicine (GUM) services have a role to play in helping reduce these risks.

It is impossible to determine the proportion of all GUM clinic workloads made up by prostitutes; in our own experience in London,

Provision of specific services for women working as prostitutes

\begin{tabular}{lc}
\hline $\begin{array}{l}\text { Combination of } \\
\text { services }\end{array}$ & $\begin{array}{l}\text { Number of clinics } \\
\text { total }=172\end{array}$ \\
\hline Outreach only & $10(6 \%)$ \\
Drop in only & $4(2 \%)$ \\
Clinic only & $2(1 \%)$ \\
Outreach and clinic & $1(1 \%)$ \\
Outreach and drop in & $3(2 \%)$ \\
Drop in and clinic & $2(1 \%)$ \\
All three & $3(2 \%)$ \\
None & $147(85 \%)$ \\
\hline
\end{tabular}

female prostitutes accounted for $6 \%$ of female attendances. Some prostitutes are reluctant to use GUM services, and when they do they may not disclose their work. ${ }^{4-6}$ This reflects fears about confidentiality, and prior experiences of moralistic and prejudiced attitudes from health and other services.

Over the past decade a number of initiatives have been taken within GUM services to reduce HIV and STD risks in the sex industry. We undertook a survey to establish the range of services provided by genitourinary medicine clinics in the UK. Questionnaires were sent to the consultant in charge of all UK GUM clinics; $172(73 \%)$ of the 237 were returned.

The majority of respondents $(119,69 \%)$ reported that female prostitutes attended their clinics. These clinics saw very few prostitutes; estimates ranged from zero to 20 (mean of 1.4) per week, with nine clinics seeing more than five. Twenty five clinics provided some form of specialist service. The breakdown of these services is shown in the table.

GUM clinics have a number of responsibilities in relation to prostitution. ${ }^{4}$ Firstly, prostitutes should have the same access to services as everyone else. Some obstacles relate to broader problems of the law and local policing, but others can be addressed within the clinic itself. These include increased awareness of prostitution and a conscious attempt to overcome prejudice in all members of staff. This should include soliciting the views of local prostitutes on the services, and staff training to address any problems. Some clinics have established drop-in facilities where prostitutes can meet staff and other prostitutes in a less formal setting to address wider health and social problems. Such centres are often very popular and may be an important way of increasing prostitutes' access to health care. Secondly, clinics with a large local sex industry should consider setting up specialist clinical services. This survey shows that only a small number of clinics $(5 \%)$ are doing this, probably reflecting the relatively small proportion of total workload thought to be represented by prostitutes. Advantages of specific clinic sessions within a GUM service include the development of trust between staff and users of the clinic, and the provision of appropriate screening and advice.

Thirdly, clinics have a responsibility, in liaison with other local agencies, to help reduce the risks of STD and HIV associated with the sex industry. It is this aspect which appears to have been most frequently addressed; $10 \%$ of clinics reported providing outreach. This outreach generally means detached health promotion work, with health advisers or other specially trained staff making contact with prostitutes outside of the clinic to provide advice, distribute condoms and facilitate visits to the clinic. Outreach work may include visits to saunas, clubs and agencies as well as to areas of street prostitution and to magistrates' courts. Through this work clinic staff can also learn about the local sex industry and assess the need for the provision of specific clinic or drop in services. 
All clinics should consider addressing the issue of health care for prostitutes, including local needs' assessments, inviting prostitutes to give their views of existing services, and providing appropriate training for all staff.

C DONEGAN

Department of Genitourinary Medicine and Communicable Imperial College School of Medicine at St Mary's,

London, UK

W DAY

Department of Epidemiology and Public Health, Imperial College School of Medicine at St Mary's, London, UK

Address correspondence to: $\mathrm{H}$ Ward, Department of Epidemiology and Public Health, Imperial College School of Medicine at St Mary's, Norfolk Place, London, UK.

1 Day $\mathrm{S}$, Ward $\mathrm{H}$. Female prostitution and sexually transmitted disease. In: Lankinen KS, Bergstrom S, Makela PH, Peltomaa M. (eds) Health and disease in developing countries. London: Macmillan Press.1994.

2 European Working Group on HIV infection in Female Prostitutes. HIV infection in European female sex workers: epidemiological link with use of petroleum-based lubricants. AIDS 1993;7:393-400

3 Ward H, Day S, Mezzone J, Dunlop L, Donegan C, Farrar $S$, et al. Prostitution and risk of HIV: female prostitutes in London. BMF 1993;307:356-8.

4 Casey M, Day S, Ward H, Ziersch A. Sexual Health Services for Prostitutes in the UK. Europap (UK), St Mary's Hospital Medical School, London. 1995.

5 Delacoste and Alexander (eds). Sex work. Writings of Women in the Sex Industry. London. Virago. 1988.

$6 \mathrm{Kinnell} \mathrm{H.} \mathrm{Prostitutes,} \mathrm{their} \mathrm{clients} \mathrm{and} \mathrm{risks} \mathrm{of} \mathrm{HIV} \mathrm{infection} \mathrm{in}$ Birmingham. Occasional paper. Central Birmingham Health Authority, 1989.

Accepted for publication 15 August 1996

\section{Self-reported discomfort associated with use of different nonoxynol-9 spermicides}

Research on the protective effect of nonoxynol-9 (N-9) spermicides against HIV infection has yielded conflicting results. ${ }^{12}$ It is possible that perceived genital irritation related to amount of N-9 per dose and frequency of $\mathrm{N}-9$ insertion modifies the association or intervenes between $\mathrm{N}-9$ use and HIV risk. Spermicide-associated discomfort can also affect the acceptability of vaginal products and the consistency of their use. We report here on self-reported genital discomfort in a study of barrier contraceptive use by couples discordant on HIV serostatus in Lusaka, Zambia. $^{3}$

STD clinic attenders found to be HIV-positive brought in their regular sexual partners for testing. Both members of volunteer serodiscordant couples were counselled and instructed on the use of male condoms and spermicides. Interviews and physical examinations ensued.
They were supplied with condoms and three spermicidal products. They also were given several pictorial coital logs to maintain between visits, which recorded days on which intercourse occurred and whether the barrier methods were used. The male condoms were latex silicone-lubricated devices (with no spermicide). The three spermicide products were: melting suppositories with $100 \mathrm{mg} \mathrm{N}-9$, later supplanted by suppositories with $150 \mathrm{mg} \mathrm{N}-9$; gel with approximately $125 \mathrm{mg} \mathrm{N}-9$ per dose; and vaginal film with $70 \mathrm{mg} \mathrm{N}-9$.

Participants were scheduled for clinic visits every three months, at which time physical exams and blood tests were repeated. The follow-up interview included items on problems incurred with use of the barrier products, and recorded the coital log totals. Participation continued until HIV infection, withdrawal, loss to follow-up or end of study. Physical examinations of the women used speculum visualization only, without colposcopy. Wet mounts were done to investigate vaginal infections. Genital ulcers were determined visually without culture. The follow-up interview (during clinic visits) queried women about discomfort following spermicide use.

The 109 couples in the follow-up analysis included 79 female seronegative and 30 female seropositive couples. The vaginal film was the most popular spermicide product. All women in the study used at least one of the N-9 products. Fifty-seven percent of the couples used only one of the three types of spermicide products during their participation in the study, including 20 suppository-only users, 12 gelonly users and 30 film-only users.

Nine women reported discomfort after spermicide use; four of these women had concurrent trichomoniasis and/or candidiasis at the examination visit. Discomfort was temporally associated with each of the three spermicide products. Only one female genital ulcer was recorded.

The mean rate of spermicide-associated discomfort was fairly low ( $<1$ report per 100 woman-months) and did not differ substantially among the self-selected spermicide groups (table). The rate of self-reported discomfort was lowest among the women who used vaginal film exclusively, but the numbers are too small to be conclusive.

Regardless of which product was used, selfreported genital discomfort was rare in this study, confirming that spermicide-associated discomfort is uncommon during family planning-type use (less than once daily). ${ }^{4}$ Furthermore, women who used the film to the

Cumulative incidence and incidence rates of self-reported female genital discomfort

\begin{tabular}{|c|c|c|c|c|c|}
\hline Group & $N$ & Woman-months & $\begin{array}{l}\text { Mean insertions } \\
\text { per month }\end{array}$ & Discomfort (\%) & Rate $^{\star}(95 \%$ CI $)$ \\
\hline $\begin{array}{l}\text { All women } \\
\text { Used suppository }\end{array}$ & 109 & 1937 & $6 \cdot 7$ & $9(8 \cdot 3)$ & $0.46(0.16-0.77)$ \\
\hline $\begin{array}{l}\text { only } \\
\text { Used gel only } \\
\text { Used film only }\end{array}$ & $\begin{array}{l}20 \\
12 \\
30\end{array}$ & $\begin{array}{l}213 \\
159 \\
531\end{array}$ & $\begin{array}{l}4 \cdot 4 \\
7 \cdot 6 \\
6 \cdot 1\end{array}$ & $\begin{array}{l}2(10 \cdot 0) \\
1(8 \cdot 3) \\
1(3 \cdot 3)\end{array}$ & $\begin{array}{l}0.94(0.0-2.24) \\
0.63(0.0-1.86) \\
0.19(0.0-0.56)\end{array}$ \\
\hline
\end{tabular}

^Self-reports of discomfort per 100 woman-months; $\mathrm{CI}=$ confidence interval. 